\title{
Closing the STEM Labor Gap through a Path to Graduation for Low Income, Rural Students
}

\section{Dr. Paul D Adams, University of Arkansas}

Paul D. Adams, Ph.D. Associate Professor, Department of Chemistry and Biochemistry Associate Professor, Cellular and Molecular Biology Distinguished Faculty Member, The Honors College University of Arkansas 119 Chemistry Building phone:(479)575-5621 email: pxa001@uark.edu Fayetteville, Ar. 72701 website: http://chemistry.uark.edu/4881.php

Dr. Paul D. Adams is a native of Baton Rouge, Louisiana. He earned a B.S. in biochemistry from Louisiana State University, and a Ph.D. in biophysical chemistry from Case Western Reserve University. Currently, Adams is an Associate Professor of Chemistry and Biochemistry, as well as Cellular and Molecular Biology at the University of Arkansas, Fayetteville (UAF). At UAF, Adams studies the biochemistry and biophysics of proteins that play roles in the onset of cancer, and his research has garnered more than $\$ 3,000,000$ in funding from the National Institutes of Health $(\mathrm{NIH})$, the National Science Foundation (NSF), the Arkansas Biosciences Institute (ABI), the Arkansas Science and Technology Authority (ASTA), and the Winthrop P. Rockefeller Cancer Institute since 2007.

\section{Xochitl Delgado Solorzano, University of Arkansas}

Xochitl Delgado Solorzano is the director of the Honors College Path Program at the University of Arkansas. In this capacity she oversees all aspects of the Path Program, including recruitment and student success, grant requirements, and fundraising.

\section{Dr. WENJUO LO, University of Arkansas}

Dr. Wen-Juo Lo is an Associate Professor in the Educational Statistics and Research Methodology (ESRM) program at the University of Arkansas. His research interests involve methodological issues related to analyses with a focus on psychometric methods. The recent research agenda concentrates statistical methods for the detection of bias in psychological measurement, especially measurement invariance on latent factor models. In addition, he also conducts research to develop effective latent variable model and instrument that reflects the factors of college students' retention.

\section{Dr. Carol S Gattis, University of Arkansas}

Dr. Carol Gattis is the Associate Dean Emeritus of the Honors College and an adjunct Associate Professor of Industrial Engineering at the University of Arkansas. Her academic research focuses on STEM education, developing programs for the recruitment, retention and graduation of a diverse population of students, and infusing innovation into engineering curriculum. Carol is also a consultant specializing in new program development. She earned her bachelor's, master's and Ph.D. degrees in Electrical Engineering from the $\mathrm{U}$ of $\mathrm{A}$ and has served on the industrial engineering faculty since 1991.

\section{Jennie S Popp Ph.D., University of Arkansas Honors College}

Jennie Popp, Ph.D. is a Professor of Agricultural Economics and the Associate Dean of the Honors College at University of Arkansas. As Associate Dean, Dr. Popp contributes to student success initiatives through the management of Honors College study abroad and research grant programs, the facilitation of the development of service learning and other new courses, promotion of undergraduate research activities and in contributions to the PTG and Honors College Path programs. Her research has focused on identification and implementation of sustainable agricultural best management practices. She has been the lead or co-principle investigator on over \$20 million in federally competitive grants to support her research. 


\section{Closing the STEM Labor Gap Through a Path to Graduation (PTG) for Low Income, Rural Students}

The current shortage of STEM graduates has highlighted the importance for novel approaches to increasing the pool of intellectual talent [1]. These approaches can be expected to lead to increased recruitment of, and facilitating pathways to, success in the number of STEM graduates. The state of Arkansas has consistently ranked near the bottom, in comparison to all 50 US states in college attendance, as well as the number of Bachelor of Science degrees awarded in engineering and science degrees awarded [2]. The Path to Graduation (PTG) program at the University of Arkansas in Fayetteville (UA) aims to increase the number of low-income students, including students from rural regions of Arkansas, who graduate with a STEM degree. These students have been recruited from the Arkansas Delta and other rural, impoverished areas of the state where opportunities to study STEM are extremely limited. The targeted students are also those which do not normally qualify for large UA scholarships due to their modest ACT/SAT scores (ACT 23-27 or SAT 11301300). The program has adapted previously implemented, evidence-based academic, financial, and social support initiatives to help these students thrive and succeed in their UA STEM studies. Currently, PTG is supporting two cohorts of STEM scholars who have met academic and financial requirements to participate in the program. The first cohort started as first-year students in Fall 2018, the second in Fall 2019. Although at UA admission, these students were ineligible for honors studies due to their test scores, the PTG team has provided various support mechanisms to facilitate the success of these students academically such that they may hopefully become eligible to enroll in the Honors College at UA at some point during program participation. The program has also provided support to encourage PTG students to continue their STEM studies in graduate school upon the completion of the PTG program. The short-term goals of this program are to support the financial needs of students from our targeted demographic and provide them with academic support and mentorship to allow them to succeed. The long-term goals of the PTG program are to increase the size, as well as diversity, of the Arkansas and US STEM labor markets. By adapting and applying previously implemented, successful student retention programs for these students, experiences of the PTG program are also expected to highlight best practices for improving academic outcomes for rural low-income high achieving STEM students that may be adapted in similar regions throughout the US.

To reach our goals under the auspices of the PTG program, we seek to answer the following questions. First, can the PTG support initiatives significantly increase the likelihood of first-year and second-year student retention for low-income STEM students as compared to their income/high school GPA-ACT (or SAT)/geography-matched peers within STEM? Rural Arkansas has experienced economic hardships that have severely limited STEM education-related resources for K-12 students as school systems in these areas have continued to struggle financially [3]. Data have also shown that students from rural areas receive limited exposure to academic enrichment programs. This can lead to lower levels of confidence as well as the belief that they are not prepared to be successful in STEM programs [4]-[11]. Secondly, can the PTG support initiatives significantly increase the average first-year and second-year GPA for low-income STEM students as compared to their income/high school GPA-ACT/geography-matched peers within STEM? It has been shown that rural Arkansas schools are faced with challenges in trying to meet mandated curriculum standards. Currently, very few rural schools in Arkansas possess the resources to offer pedagogical approaches, such as Advanced Placement (AP) courses. This can 
result in rural students being less academically prepared than students from urban communities, and seemingly deflated GPAs in comparison to weighted GPAs that benefit from AP courses [12]. This, in addition to resulting lower standardized test scores, has led to students from rural regions becoming less competitive for academic scholarships in comparison to students from urban areas where AP course are much more abundant [12]-[14]. Therefore, to help answer the abovementioned questions, the following objectives are currently being pursued under the umbrella of the PTG program:

Objective 1. Establishment of a consistent PTG recruitment program at UA using best practices from previous successful programs used by the University's College of Engineering and the Honors College (HC), and award S-STEM scholarships to selected low-income students each year of the program who demonstrate academic promise.

Objective 2. Facilitation of an increase in PTG students' social engagement through participation in peer mentoring and living-learning communities.

Objective 3. Guidance of PTG students' academic engagement via faculty-student interaction, academic success advising, academic enrichment programs, and accelerated student achievement programs.

\section{Establishing Consistent PTG Recruitment and S-STEM Scholarship Awarding.}

During the first two years of the program, we have been able to award PTG scholarships to 27 students from the identified demographic (short of our proposed goal of 36) in two cohorts. Cohort 1 included 14 students who enrolled for the Summer 2018/2019 semester with an average cumulative high school GPA of 3.90. Approximately $72 \%$ students were from rural communities, and $\sim 36 \%$ were first-generation students. In the Fall of 2019, Cohort 2 consisted of 13 students who were awarded PTG scholarships. For this cohort, the average cumulative high school GPA was 4.01, with all students being from rural communities, and $\sim 36 \%$ being first-generation college students. As has been discussed, all accepted students to the PTG program possessed a great financial need as displayed by their eligibility for the Pell grant and/or the Subsidized Stafford Loan programs [1]. Each accepted student received scholarships of up to $\$ 4,500$ for those who had not joined the $\mathrm{HC}$, and up to $\$ 5,500$ for those that did join the HC. Our success in recruitment has been due to the implementation of the NSF-funded S-STEM program Breaking Barriers/Engineering Career Awareness Program (ECAP) [DUE1154146] fall recruitment best practices, as well as HC best practices. The Honors College has three Honors College recruiters, including one who now specializes in first generation/small town recruitment who met with prospects across the state. To aid with our year 2 recruitment efforts, we encouraged current PTG students, in addition to our recruiting staff, to send recruitment emails and make personal phone calls in order to encourage potential applicants and answer questions about the program. Moreover, the recruitment of both cohorts included a collaboration and coordination with the ECAP interview weekend, which led to a PTG interview weekend that was developed for and attended by PTG finalists and family members. The weekend included interviews, information on the PTG program, the UA community, as well as opportunities for students through the PTG program and the $\mathrm{HC}$. Also conducted during this weekend were financial aid, mentoring, diversity and inclusion and Q\&A sessions. The PTG interview weekend was free of cost to the student and 
families and sponsored by the HC. Finalists' interviews were held with interview panels that consisted of a PTG team member, an industry representative, and a student representative. Once award notifications were made, follow up communications were conducted by phone and emails to answer any questions the students and their families may have had before committing to the program.

\section{Addressing PTG Students' Social Engagement Through Peer Mentoring and Living Learning} Communities.

Transitioning from high school to a university setting is a challenge for most students, no matter their socio-economic or demographic background. For first-year college students, the development of organization and time management skills, adjusting to university styles of learning, the management of study and social schedules, as well as the development of social networks can be challenging [15]. To help lessen the potential anxieties associated with this transition, several peermentoring opportunities have been established for PTG students. Also, both cohorts of students in the PTG program have been required to live on campus in the $\mathrm{HC}$ residence hall, Hotz Hall, for their first year at UA. Peer-mentoring relationships were started during the summer bridge program that all participants experienced prior to their first semester at the university. The peer mentoring continued into the first-year with participants meeting twice a month with their respective peer mentors, although peer mentors have been and will continue to remain available for consultation. In addition, PTG participants were required to attend two $\mathrm{HC}$ events during each semester as part of the living-learning communities where they lived.

Guiding PTG Students' Academic Engagement via Faculty Interaction(s), Academic Success, Enrichment Advising, Student Achievement and Adaptation of Programs, Bridge Program.

To engage faculty mentorship, students have been encouraged to participate in research clusters based on their research interest. Each cluster was assigned a faculty mentor that worked to expose students to different types of research and presentations. In addition, the research clusters remained intact through the fall and spring semesters to try and develop an intellectual continuity for each PTG student during the first-year. Over the course of year 1, this approach showed limited success as: 1) scheduling between both scholars and mentors was difficult to synchronize and; 2) as new university students, scholars had difficulty understanding the full relevance and importance of the research to which they were being exposed. For Cohort 2, this model was modified. In conjunction with the HC First-Generation mentoring program, Cohort 2 PTG scholars have been assigned their own mentor, based on their major, whose role is to support the student in navigating their first year at the university and providing guidance for long-term career planning. Cohort 2 PTG cluster socialization has been effectively achieved through the PTG monthly meetings rather than through research groups. For each cohort, however, PTG scholars met with PTG staff for a mid-semester review. During this review, each student's academic progress and plan for academic improvement for the second half of the semester is discussed. This approach has proven to be highly successful in helping PTG scholars anticipate academic challenges, taking proactive steps to minimize difficulties before they arise, and become comfortable interacting with professors during office hours. 
A second approach to facilitating success and achievement for PTG students has been the facilitation of monthly PTG meetings throughout the fall and spring semesters that have covered a variety of topics for academic improvement. The goal of these meetings has been to provide both information and time for community building. At the outset, meetings were deemed to be too heavily programmed, leaving little room for community building and social networking. During year 2 however, programming topics have been streamlined to better provide a balance of information and community building/networking opportunities. Some topics presented have included: Negotiating your college experience; Diversity and Inclusion Training; Mentee Training; How to interact with faculty; Long-term planning and academic mapping; Service Learning; One Book One Community Discussions; Service Learning; Career Development; Resume writing; Failure and Resiliency discussions; Preparations for Graduate and/or Professional school; How to Apply for Nationally Competitive Awards; and Maintaining Grit, Health and Wellness during Challenging Times. Some of the topics developed for the monthly meetings were adapted from the NSF-funded S-STEM program and the Student Integrated Intern Research Experience (SIIRE) [DUE 1154146] workshop curriculum (https://siire.uark.edu). The diversity and inclusion and mentee training sessions were especially successful in that they taught PTG students the benefits and self-responsibilities of being mentored and interacting with faculty who may have a different background than theirs. The above-mentioned approaches helped provide quality programmatic components mentioned in the objectives and were adapted to maximize their effectiveness for this group of students (i.e. faculty mentoring, professional mentoring, monthly meetings, mid-semester reviews, and social activities).

The PTG bridge program provides a supportive academic community for students as they pursue 6-7 credit hours (full-time status) in the 5-week summer session immediately prior to their first fall semester. The credit hours allow PTG students to get up to speed to start their studies at the level of the majority of their STEM peers. They also all take a 1-credit hour research course [1].

\section{Success and Impact.}

The overall goals of this PTG program has been to foster an increase in the number of STEM graduates by recruiting from a demographic that has not been significantly targeted, rural students with financial need. To date, we have been moderately successful in understanding some of the challenges of this student demographic and have put in place mechanisms to hopefully minimize previous barriers to success, and to aid the students to perform at their highest levels. Success and impact have been shown by the following data of our current PTG scholars:

- $\quad$ The post-summer bridge program (6 or 7 credit hours) average GPA was 3.76 for Cohort 1 compared to 3.93 for Cohort 2;

- The average cumulative 1 st semester GPA for Cohort 1 was 2.58 compared to 3.35 for Cohort 2;

- $\quad$ The average cumulative 1 st year GPA for Cohort 1 was 2.925;

- $\quad 22 \%$ (3) of cohort 1 students have met honors enrollment requirements after the 20182019 academic year of which 2 have enrolled; 
- $\quad \sim 62 \%$ (9) of cohort 2 students have met honors enrollment requirements after their first semester (fall 2019) of which 6 have enrolled;

- $\quad$ 14\% (2) of Cohort 1 students have begun faculty guided undergraduate research in their 2nd year of matriculation;

In examining the data above, it is of note that none of the PTG students entered the university as Honors eligible, so reaching $\mathrm{HC}$ level of academic achievement is substantial, particularly doing so in their first year while adjusting to college. To become $\mathrm{HC}$ eligible once at UA, a student must reach a cumulative GPA of 3.50 or greater. Not all HC eligible students chose to enroll in the HC at this point, due to lack of confidence that they can complete the rigors of the honors program (honors courses and honors research). It will be interesting to see if their confidence increases as they become more mature in their STEM programs. The improved first-year success of Cohort 2 in comparison to Cohort 1 can be explained by adjustment of the PTG program based on lessons learned from year 1, including the following factors: 1) for Cohort 2 scholars entering the fall 2019 semester, a majority of the engineering students did not enroll in chemistry, physics, and calculus simultaneously. This allowed for more quality time to prepare for all of their course work during this semester which was important due to their reduced level of academic preparation for these classes during high school; 2) better recruitment of students from the rural populations for Cohort 2, including having a full recruitment cycle to recruit; 3) adjustment of retention programming based on lessons learned from the previous year with Cohort 1 scholars; and 4) additional experience of staff in dealing with rural students with financial need. Moreover, PTG staff members have guided PTG students as they adjust their academic habits and preparation by addressing topics such as: time management, best practices in study habits, prioritization of activities, development of school/life balance, and goal setting.

It is of note that for Cohort 1, 14 PTG scholars were admitted for the 2018-2019 academic year, and 8 remain. For the 2019-2020 academic year, Cohort 2 had 13 PTG scholars admitted with 12 remaining. This work has been impactful in also noting that all remaining students are currently making progress towards a B.S. degree, primarily in engineering, chemistry, biology, and physics.

Another goal of the present study comparing between PTG and Non-PTG students was twofold. First, we used the matched group (i.e., Non-PTG students) to compare with PTG students' persistence. Second, following the Tinto's retention model, we evaluated the longitudinal survey data that included 13 subscales. The survey was deployed during the fall 2018 and spring 2019 semesters. Since we only had one semester data for the PTG Cohort 2019, the following analyses were only used Cohort 2018's data.

\section{Study 1: Retention}

\section{Participants \& Procedures}

According to University Data Warehouse, there were 1,298 students [797 (61.4\%) male and 501 (38.6\%) female] declared and enrolled in the STEM majors. Since PTG focuses on students who came from rural areas and minority groups, it was decided to put more weights on several 
demographic characteristics when the matched group (i.e., control group) was selected instead of using a completely random assignment. First, to avoid missing potential latent personal characteristics, we used one to five ratios (i.e., selected 5 Non-PTG students for each PTG student) to generate our comparable group instead of just using paired matching. Second, several specific criteria of similarity were considered, such as sex, permanent residence zip code (i.e., proportion rural zip code), ACT composite scores (i.e., ranged from 23 to 28), high-school GPA (i.e., ranged from 3.35 to 4.11 ), and minority groups. The function of PROC SURVERYSELECT was used with strata selection from SAS 9.4 to align with PTG students' demographic information. However, there was a limited number of students who met both criteria (i.e., rural location and non-White). Out of 1298 STEM students in the UA's 2018 cohort, only 158 (12.2\%) came from rural areas, only $367(28.3 \%)$ were non-white. Demonstrating the need to recruit more rural minority students into STEM, only 40 STEM students were both non-white and rural, of which 11 (27.5\%) were recruited by PTG. As can be seen in Table 1, the PTG group has a much higher proportion of minority students compared to the match group. This results from the small number of rural, non-white STEM students which is then filtered further by GPA and ACT/SAT. Table 1 presented the closest match based on stratified random sampling.

\section{Analyses and Results}

Given that the outcome of student persistence after first-year was dichotomous (persist or withdraw), a two-way contingency table analysis with Fisher exact test was applied to evaluate whether PTG students were more persistent than Non-PTG students. The dependent variable is student's persistence, determined by whether students consistently enrolled in their sophomore year disregarding whether they changed their majors or not. The results indicated that for their first year, PTG status and persistence were not statistically significant $(p=.378)$. Although the results were nonsignificant, it remains to be seen whether PTG participation will impact retention in sophomore through senior years. Also, it is possible that the insignificance could be due to the matched group having higher proportions of students that come from rural and non-white populations, given that both of these are risk factors at UA.

Table 1

Demographic and Other Variables for Participants $(N=86)$

\begin{tabular}{|c|c|c|c|c|}
\hline \multirow[b]{2}{*}{ Variables } & \multicolumn{2}{|c|}{$\begin{array}{l}\text { PTG } \\
(n=14)\end{array}$} & \multicolumn{2}{|c|}{$\begin{array}{l}\text { Non-PTG } \\
(n=70)\end{array}$} \\
\hline & Count & $\%$ & Count & $\%$ \\
\hline \multicolumn{5}{|l|}{ Persistence } \\
\hline Persisted & 12 & 85.7 & 54 & 77.1 \\
\hline Did not persisted & 2 & 14.3 & 16 & 22.9 \\
\hline \multicolumn{5}{|l|}{ Gender† } \\
\hline Male & 7 & 58.3 & 37 & 52.9 \\
\hline
\end{tabular}


$\begin{array}{lllll}\text { Female } & 5 & 41.7 & 33 & 47.1\end{array}$

Race†

$\begin{array}{lllll}\text { White } & 4 & 28.6 & 29 & 41.4\end{array}$

$\begin{array}{lllll}\text { Others } & 10 & 71.4 & 41 & 58.6\end{array}$

Permanent Residence†

\begin{tabular}{lllll} 
Rural & 11 & 78.6 & 33 & 52.9 \\
Others & 3 & 21.4 & 37 & 47.1 \\
\hline & $\boldsymbol{M}$ & $\boldsymbol{S D}$ & $\boldsymbol{M}$ & $\boldsymbol{S D}$ \\
\hline HS GPA & 3.90 & .19 & 3.82 & .17 \\
ACT composite scores & 26.07 & 1.64 & 25.64 & 1.62 \\
\hline
\end{tabular}

† Marked variables were used for stratified random sampling. PTG and Non-PTG proportion could not matched due to limited number of students from the rural area.

\section{Study 2: Retention}

\section{Participants \& Procedures}

Insights on PTG's impact will also be inferred by comparing PTG students with students not involved in PTG but with similar academic disciplines and demographics. To assess program effectiveness, the PTG team adapted Tinto's student retention model and assembled the baseline survey which administered at the first month of the fall semester (2018) and the follow-up survey which conducted at the midpoint of the spring semester (2019). Initially, the baseline survey had 1,219 students answered and the follow-up survey had 764 responses. Prior to using these data in statistical models, we applied two-stage data cleaning and matched group selection. First, we examined the proportion of missing surveys across various scales that may impact further analyses. We also removed students who only responded to either the baseline or the follow-up survey. After combining usable background information and both student surveys, the first-stage sample included 325 students (included only 11 PTG students who completed both surveys), or $26.67 \%$ of the initial survey respondents. The second stage that was conducted involved matched group selection similar to the procedures that had been used in Study 1. We applied the same criteria and one to five ratios to select our matched group, the final sample included 66 students. See Table 2 for their demographic information, ACT composite scores and high school GPA.

\section{Measures}

These surveys involving eleven subscales (See Table 3 for details) were developed or adapted from existing validated surveys. Two subscales (initial perceived social support and pre-college schooling) were surveyed only in the first semester, and two subscales (academic/social 
integration and institutional experiences) were only surveyed only in the second semester. The remaining seven subscales (academic self-efficacy, career self-efficacy, self-regulation, perceived social support, goal commitment, institutional commitment, and desire to finish college) were surveyed each semester for the duration of the project.

\section{Analyses and Results}

A series of independent-sample t-tests were conducted to evaluate whether or not student's prescriptions, measured by 4 scales (i.e., initial perceived social support, pre-college schooling, academic/social integration, and institutional experiences), were different between PTG and Non-PTG students. In addition, a factorial analysis of variance (ANOVA) with repeatedmeasures factors and between-subjects factors was conducted to evaluate whether or not students' prescriptions changed across semesters between PTG and Non-PTG students which measured by 7 subscales mentioned in previous section. The results were summarized below:

\section{[Independent t-test]}

- Initial perceived social support: the test was not significant, $t(27.489)=1.891, \mathrm{p}=.069$. However, PTG students have shown higher score in average $(\mathrm{M}=4.77, \mathrm{SD}=.28)$ than the Non-PTG students $(\mathrm{M}=4.55, \mathrm{SD}=.54)$.

- Pre-college schooling: the result test was nonsignificant, $t(64)=-.404, \mathrm{p}=.688$. Not surprisingly, Non-PTG students have slightly higher score in average $(\mathrm{M}=3.34, \mathrm{SD}=.39)$ than the PTG students $(\mathrm{M}=3.28, \mathrm{SD}=.36)$.

- Academic/social integration: Again, the result was nonsignificant, $t(64)=.209, \mathrm{p}=.835$.

- Institutional experiences: the test was nonsignificant, $t(64)=-.677, \mathrm{p}=.501$.

\section{[MANOVA]}

- Academic self-efficacy: The main effect was significant, $\Lambda=.675, F(1,64)=30.788, p<$ .001 . It indicated both groups had higher score in average in the second semester then the first semester. However, there was no significant differences between groups.

- Career self-efficacy: The test was significant, $\Lambda=.920, F(1,64)=5.598, p=.021$. Again, the results indicated the scores were increased in average in the second semester, but there was no significant difference between groups.

- Self-regulation: The main effect was significant, $\Lambda=.883, \mathrm{~F}(1,64)=8.519, \mathrm{p}=.005$. Interestingly, the PTG students self-reported that their self-regulation decreased in average in the second semester. In contrast, the Non-PTG student did not have significant change.

- Perceived social support: The test was nonsignificant, $\Lambda=.989, \mathrm{~F}(1,64)=.721, \mathrm{p}=.399$.

- Goal commitment: The result was nonsignificant, $\Lambda=.941, \mathrm{~F}(1,64)=3.994, \mathrm{p}=.051$.

- Institutional commitment: The result was nonsignificant, $\Lambda=.968, \mathrm{~F}(1,64)=2.119, \mathrm{p}=.150$.

- Desire to finish college: The main effect was significant, $\Lambda=.898, \mathrm{~F}(1,64)=7.254, \mathrm{p}=.009$. It indicated both groups had higher score in average in the second semester then the first semester. However, there was no significant differences between groups.

The scales measured in the presurvey did not show significant differences that matched the researchers' expectations. A greater improvement or change in the post-survey was expected, but the results were not supported either. The possible reason is that there were limited STEM 
students that came from the rural area and the matched group somehow did not match completely with the PTG demographic.

Table 1

Demographic and Other Variables for Participants $(N=66)$

\begin{tabular}{|c|c|c|c|c|}
\hline \multirow[b]{2}{*}{ Variables } & \multicolumn{2}{|c|}{$\begin{array}{c}\text { PTG } \\
(n=11)\end{array}$} & \multicolumn{2}{|c|}{$\begin{array}{c}\text { Non-PTG } \\
\quad(n=55)\end{array}$} \\
\hline & Count & $\%$ & Count & $\%$ \\
\hline \multicolumn{5}{|l|}{ Gendert } \\
\hline Male & 6 & 54.5 & 20 & 36.4 \\
\hline Female & 5 & 45.5 & 35 & 63.6 \\
\hline \multicolumn{5}{|l|}{ Racet } \\
\hline White & 3 & 27.3 & 23 & 41.8 \\
\hline Others & 8 & 72.7 & 32 & 58.2 \\
\hline \multicolumn{5}{|l|}{ Permanent Residence $†$} \\
\hline Rural & 8 & 72.7 & 10 & 18.2 \\
\hline \multirow[t]{2}{*}{ Others } & 3 & 27.7 & 45 & 81.8 \\
\hline & $M$ & $S D$ & $M$ & $S D$ \\
\hline HS GPA & 3.96 & .16 & 3.74 & .21 \\
\hline ACT composite scores & 25.91 & 1.70 & 25.60 & 1.58 \\
\hline
\end{tabular}

† Marked variables were used for stratified random sampling. PTG and Non-PTG proportion could not matched due to limited number of students from the rural area. 
Table 2

Descriptions of Each Scale

\begin{tabular}{|c|c|c|c|}
\hline $\begin{array}{l}\text { Factor } \\
\text { Construct }\end{array}$ & Definition & \# of Item & Possible Score Range \\
\hline $\begin{array}{c}\text { Academic } \\
\text { self-efficacy }\end{array}$ & $\begin{array}{l}\text { Self-evaluation of one's ability and/or } \\
\text { chances for success in the academic } \\
\text { environment (Robbins, Lauver, Davis, } \\
\text { Langley, \& Carlstrom, 2004). }\end{array}$ & 10 & $\begin{array}{l}10-50 \\
\text { 5-point Likert type }\end{array}$ \\
\hline $\begin{array}{c}\text { Career } \\
\text { self-efficacy }\end{array}$ & $\begin{array}{l}\text { It identifies the extent to which } \\
\text { students has self-efficacy about their } \\
\text { abilities to engage in educational and } \\
\text { occupational information gathering, } \\
\text { goal planning, and decision- making } \\
\text { (Taylor \& Betz, 1983). }\end{array}$ & 4 & $\begin{array}{l}\text { - Yes/No: } 1 \text { item } \\
\text { - 4-point: } 1 \text { item } \\
\text { - 5-point: } 2 \text { items }\end{array}$ \\
\hline Self-regulation & $\begin{array}{l}\text { It refers to the awareness, knowledge, } \\
\text { and control of cognition. It also } \\
\text { includes students' ability to control } \\
\text { their effort and attention in the face of } \\
\text { distraction and uninteresting tasks } \\
\text { (p.23 \& p. } 27, \text { MSLQ Manual; } \\
\text { Pintrich, Smith, Garcia, \& } \\
\text { McKeachie, 1991). }\end{array}$ & 8 & $\begin{array}{c}8-56 \\
\text { 7-point Likert type }\end{array}$ \\
\hline $\begin{array}{l}\text { Perceived social } \\
\text { support }\end{array}$ & $\begin{array}{l}\text { Students' perception of the } \\
\text { availability of the social networks that } \\
\text { support them in college. (Robbins, } \\
\text { Lauver, Davis, Langley, \& Carlstrom, } \\
\text { 2004). }\end{array}$ & 12 & $\begin{array}{c}12-60 \\
\text { 5-point Likert type }\end{array}$ \\
\hline
\end{tabular}




\begin{tabular}{|c|c|c|c|}
\hline Factor Construct & Definition & $\begin{array}{c}\# \text { of } \\
\text { Item }\end{array}$ & Possible Score Range \\
\hline $\begin{array}{l}\text { Initial perceived } \\
\text { social support }\end{array}$ & $\begin{array}{l}\text { Students' perception of the } \\
\text { availability of the social networks } \\
\text { that support them in college. } \\
\text { (Robbins, Lauver, Davis, Langley, \& } \\
\text { Carlstrom, 2004). }\end{array}$ & 4 & $\begin{array}{c}4-20 \\
\text { 5-point Likert type }\end{array}$ \\
\hline $\begin{array}{c}\text { Goal } \\
\text { commitments }\end{array}$ & $\begin{array}{l}\text { One's persistence with and } \\
\text { commitment to action, including } \\
\text { general and specific goal-directed } \\
\text { behavior, in particular, commitment } \\
\text { to attaining the college degree; one's } \\
\text { appreciation of the value of college } \\
\text { education. }\end{array}$ & 6 & $\begin{array}{c}6-30 \\
\text { 5-point Likert type }\end{array}$ \\
\hline $\begin{array}{c}\text { Institutional } \\
\text { commitments } \\
\text { Commitment to } U A\end{array}$ & $\begin{array}{l}\text { Students feel committed to the } \\
\text { college they are currently enrolled in; } \\
\text { their overall attachment to college. }\end{array}$ & 2 & $\begin{array}{c}2-10 \\
\text { 5-point Likert type }\end{array}$ \\
\hline $\begin{array}{l}\text { Institutional } \\
\text { commitments } \\
\text { Desire to Finish } \\
\text { College }\end{array}$ & $\begin{array}{l}\text { Students' confidence of and } \\
\text { satisfaction with their institutional } \\
\text { choice }\end{array}$ & 6 & $\begin{array}{c}7-42 \\
\text { 7-point Likert type }\end{array}$ \\
\hline $\begin{array}{l}\text { Pre-college } \\
\text { schooling }\end{array}$ & Activities in high school & 8 & $\begin{array}{c}8-40 \\
\text { 5-point Likert type }\end{array}$ \\
\hline
\end{tabular}

\section{Summary}

The NSF-S-STEM funded Path to Graduation (PTG) program has sought to reach deep into rural areas of the state of Arkansas to recruit and attract students from low-income and/or underrepresented populations into STEM majors. This has proven to be successful, considering 11 $(27.5 \%)$ of the 40 rural and non-white STEM students at UA for this cohort were recruited by PTG; and 14 (8.9\%) of the 158 rural STEM students were recruited by PTG. It has been a learning process; in working with this population of students, PTG staff and faculty mentors have learned how to better serve rural student populations over the last year. Through various programming efforts, students are being exposed to professional development and experiences that will help 
them be more prepared to enter the workforce or graduate school. It is felt that the program will eventually lead to an influx of a more diverse workforce in terms of critical thought development, and cultural experiences that can educate other community members. Through recruitment, aspects of the PTG program have helped to expose teachers, students and parents to the benefits of higher education in communities that have had few people with education beyond high school. The retention rate of this student demographic, at the undergraduate level, remains to be seen, but will hopefully, ultimately, foster increased graduation rates, and will increase the number of STEM graduates entering the STEM workforce in the state of Arkansas, as well as regionally, nationally and globally.

This material is based upon work supported by the National Science Foundation under Grant No. 1742496. Any opinions, findings, and conclusions or recommendations expressed in this material are those of the author(s) and do not necessarily reflect the views of the National Science Foundation. 


\section{References}

[1] C. Gattis, P. A., M. Cleary, X. Delgado Solorzano, J. Popp, D. Nix, and B. Hill, "Work in Progress: A Path to Graduation: Helping First-Year Low Income, Rural Engineering Students Succeed," Proceedings of the 2019 ASEE Annual Conference \& Exposition, 2019.

[2] Arkansas Department of Education, ADE Data Center, 2018.

[3] University of Arkansas Division of Agriculture Research and Extension, "Rural Profile of Arkansas 2015: Social and Economic Trends Affecting Rural Arkansas," University of Arkansas Cooperative Extension Service Printing Services, United States Department of Agriculture, University of Arkansas, and County Governments Cooperating, 2015. www.uaex.edu/publications/pdf/MP-531.pdf

[4] A. Bandura, "The explanatory and predictive scope of self-efficacy theory," J Clin and Soc Psyc, 4(3), 359-373, 1986.

[5] T. Bouffard-Bouchard, "Influence of self-efficacy on performance in a cognitive task," J Soc Psyc, 130(3):353-363, 1990.

[6] D. Cervone, P. Peaker, “Anchoring, efficacy, and action: The influence of judgmental heuristics on self-efficacy judgments and behavior," J Personality and Soc Psych, 50(3):492-501, 1986.

[7] M. Chemers, L. Hu, and B. Garcia, "Academic self-efficacy and first-year college student performance and adjustment," J Ed Psych, 93(1):55-64, 2001.

[8] N. Ware, and V. Lee, "Sex differences in choice of college science majors," Am Ed Res J, 25(4):593-614, 1988.

[9] R. Marra, K. Rodgers, D. Shen, and B. Bogue B, "Women engineering students and self-efficacy: a multi-year, multi-institution study of women engineering student self-efficacy," $J$ of Eng Edu, 98(1):27-38, 2009.

[10] S. Maple, F. Stage, "Influences on the choice of math/science major by gender and ethnicity," Am Ed Res J, 28(1):37-60, 1991.

[11] D. Schunk, "Modeling and attributional effects on children's achievement: A self-efficacy analysis," J Ed Psych, 73(1):93-105, 1981.

[12] W. Willingham, C. Lewis, R. Morgan, and L. Ramist, "Predicting college grades: an analysis of institutional trends over two decades," Princeton NJ: Educational Testing Service, 1990.

[13] C. Lewis Ramist, and L. McCamley-Jenkins, Student group differences in predicting college grades: sex, language and ethnic groups, New York: College Entrance Examination Board, 1994. 
[14] R. Elliott, A. Stenta, R. Adair, M. Matier, and J. Scott, "Non-Asian minority students in the science pipeline at highly selective institutions," Report to the National Science Foundation, Washington, DC: National Science Foundation, 1995.

[15] B. Leidenfrost, M. Schutz, C-C. Carbon, and A. Schagmann, "The Impact of Peer Mentoring on Mentee Academic Performance: Is Any Mentoring Style Better than No Mentoring at All?," International Journal of Teaching and Learning in Higher Education, 26(1), 102-111, 2014. 